\title{
Dermatosis IgA lineal asociada a sífilis secundaria
}

\section{Linear IgA bullous dermatosis associated secondary syphilis}

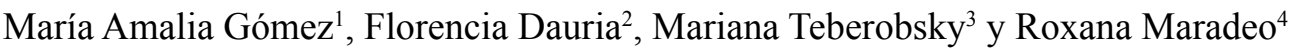

\begin{abstract}
RESUMEN
La dermatosis IgA lineal del adulto es una enfermedad que pertenece al grupo de las dermatosis ampollares adquiridas. De etiología desconocida e infrecuente, se presenta en adultos mayores y se asocia a múltiples fármacos, neoplasias y enfermedades autoinmunes e infecciosas.
\end{abstract}

Se presenta el caso de un paciente con una dermatosis IgA lineal asociada a una sífilis secundaria.

Palabras clave: dermatosis IgA lineal del adulto, sífilis secundaria.

Dermatol. Argent. 2021, 27 (1): 25-27

\section{ABSTRACT}

Linear bullous IgA dermatosis of adult is a disease that belongs to the group of acquired bullous dermatoses. It is of unknown aetiology and infrequent in adults and is associated with drugs, neoplasms, autoimmune and infectious diseases.
We present a case of a male patient in whom a linear IgA dermatosis and secondary syphilis coexist.

Key words: linear bullous IgA dermatosis of adult, secondary syphilis.

Dermatol. Argent. 2021, 27 (1): 25-27
1 Médica de Tercer Año, Carrera de Especialista en Dermatología, Universidad de Buenos Aires

${ }^{2}$ Médica Residente de Tercer Año de Dermatología

${ }^{3}$ Médica de Planta

4 Jefa del Servicio

Servicio de Dermatología, Hospital Interzonal de Agudos José de San Martín, La Plata, Provincia de Buenos Aires, Argentina
Contacto del autor: María Amalia Gómez

E-mail: maggomez88@hotmail.com

Fecha de trabajo recibido: $4 / 6 / 2020$

Fecha de trabajo aceptado: 22/3/2021

Conflicto de interés: las autoras declaran que no existe conflicto de interés.

\section{CASO CLÍNICO}

Un paciente de 26 años, sin antecedentes patológicos conocidos, consultó por la aparición de lesiones generalizadas, de una semana de evolución, asociadas a un síndrome de repercusión general y fiebre. Sin consumo de medicamentos previos.

En el examen físico presentaba lesiones pruriginosas en la cara, el tronco y los miembros, con gran afectación de los pliegues axilares e inguina- les. Estas consistían en ampollas tensas, algunas con distribución en roseta, otras agminadas, sobre una base eritematosa, con erosiones y costras (Fotos 1 y 2). Las mucosas estaban respetadas y no se palpaban adenopatías generalizadas. Además, se veían en ambas plantas múltiples lesiones papulosas, rojo-parduzcas, menores de $0,5 \mathrm{~cm}$ de diámetro, no pruriginosas (Foto 3). 

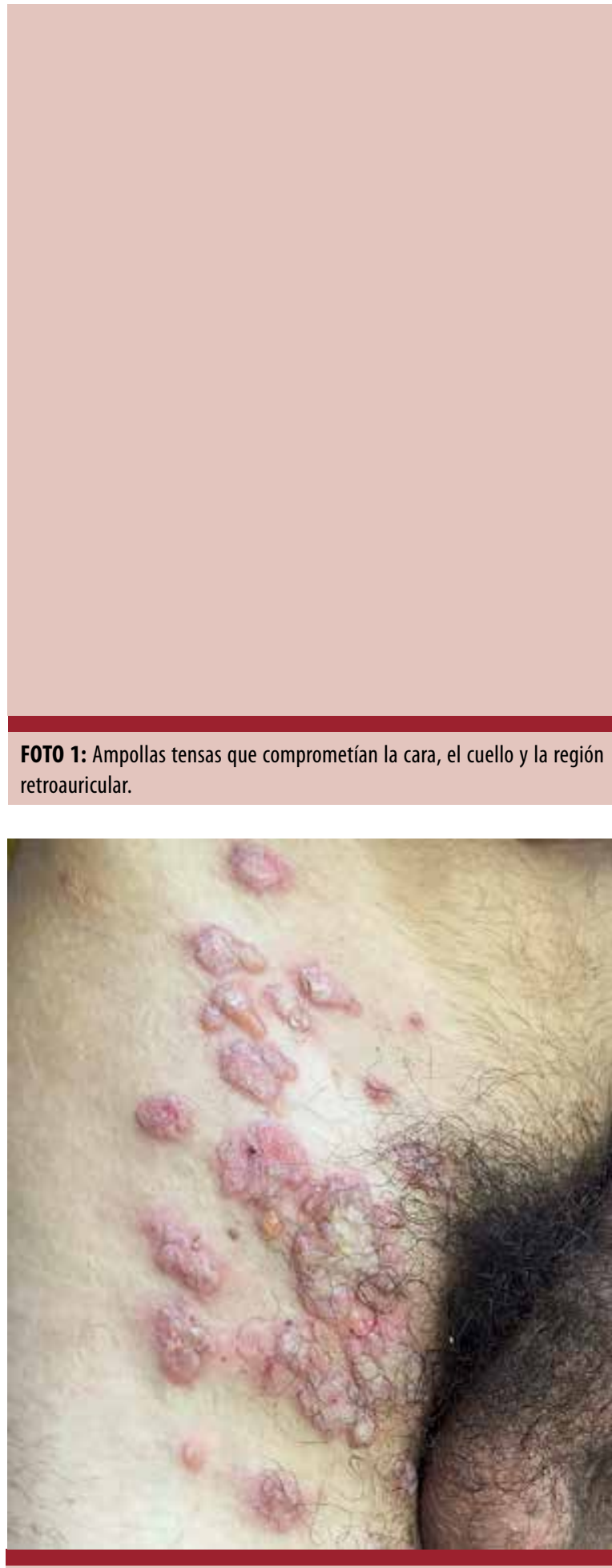

FOTO 2: Ampollas con distribución en rosetas en el pliegue inguinal.

Con el diagnóstico presuntivo de dermatosis IgA lineal y sífilis secundaria, se decidió solicitar un laboratorio de rutina con serologías, una biopsia para anatomía patológica y otra muestra para inmunofluorescencia directa (IFD) de la piel sana perilesional.

El laboratorio de rutina, las serologías y los anticuerpos anticeliaquía resultaron negativos, excepto la

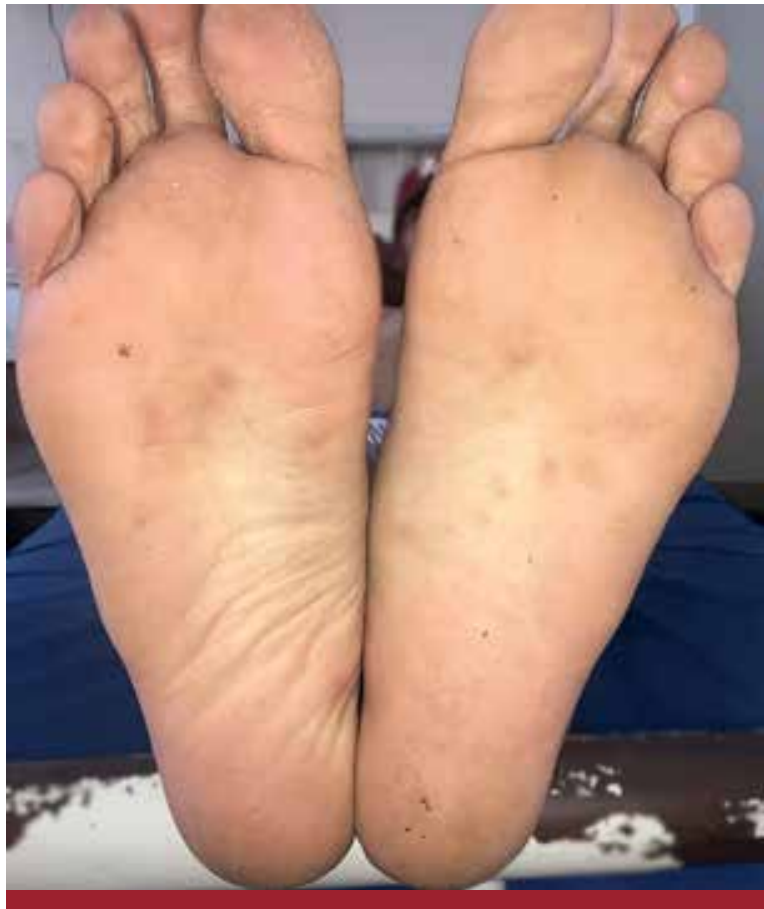

FOT0 3: Compromiso de ambas plantas.

VDRL cuantitativa, que fue de 32 dils, y un FTA-ABS reactivo.

El citodiagnóstico de Tzanck no aportó datos.

En la histopatología se evidenció una ampolla subepidérmica con neutrófilos y eosinófilos (Foto 4). La IFD mostró depósitos lineales de IgA en la unión dermoepidérmica.

Con el diagnóstico confirmado de dermatosis IgA lineal y sífilis secundaria, se inició tratamiento con dapsona $100 \mathrm{mg} /$ día, previa determinación de glucosa 6-fosfato-deshidrogenasa. Asimismo, se realizó la aplicación intramuscular de una única dosis de penicilina G benzatínica de 2.400.000 UI.

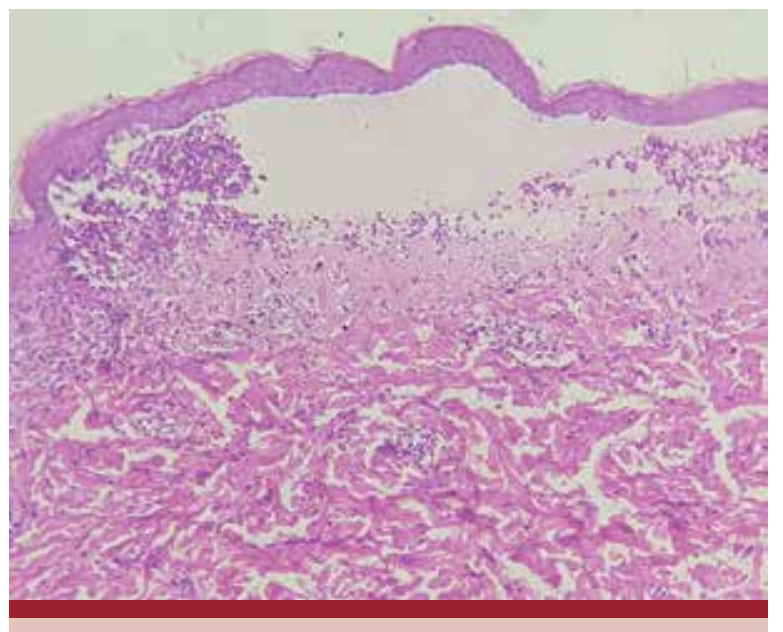

FOTO 4: Ampolla subepidérmica con contenido de neutrófilos y eosinófilos (HyE, 4X). 
El paciente evolucionó al mes de tratamiento con mejoría de las lesiones cutáneas y en los 6 meses de seguimiento sin nuevos brotes. Además, se realizó un control de laboratorio con VDRL cuantitativa a los 3 y 6 meses, y se objetivó un descenso de los valores en 4 dils.

\section{COMENTARIOS}

La dermatosis IgA lineal es una enfermedad infrecuente, ampollar, autoinmune y adquirida. Se caracteriza por la presencia de ampollas tensas y pruriginosas y por un depósito lineal de IgA a lo largo de la unión dermoepidérmica ${ }^{1,2}$.

Afecta a personas mayores de 60 ańos, con un leve predominio en las mujeres ${ }^{1}$.

El mecanismo fisiológico que desencadena la respuesta inmune se desconoce. Algunos pacientes pueden presentar un cuadro de vías aéreas superiores antes del inicio de los síntomas o también posterior a las inmunizaciones ${ }^{3-5}$.

La dermatosis IgA lineal se desencadena por la producción de anticuerpos IgA contra componentes de la membrana basal, los cuales están dirigidos contra el antígeno del penfigoide ampollar de tipo 2 (BPAG2) y los productos de degradación de este como las proteínas 97 $\mathrm{kDa}$ (LABD97) y $120 \mathrm{kDa}$ (LAD1) y el colágeno VII ${ }^{1,2}$.

Otros factores precipitantes pueden ser fármacos (antibióticos como vancomicina, AINE, anticonvulsivos, IECA), neoplasias (hematológicas; cáncer de colon, esófago y tiroides; melanoma ocular), enfermedades autoinmunes (lupus, colitis ulcerosa, artritis reumatoide, psoriasis, enteropatía sensible al gluten) e infecciones virales (virus de Epstein-Barr, citomegalovirus, virus del herpes simple, virus de la varicela zóster) y bacterianas (Salmonella enteritidis, brucelosis, Staphylococcus spp., Streptococcus spp. y Clostridium tetani) $)^{2-6}$.

Si bien la asociación con la sífilis no se ha publicado hasta el momento, como en el caso del paciente

\section{BIBLIOGRAFÍA}

1. Kasperkiewicz M, Meier M, Zillikens D, Schmidt E. Linear IgA disease: successful application of immunoadsorption and review of the literature. Dermatology 2010;220:259-263.

2. Rodríguez L, Forero OL, Olivares L, Candiz ME, et ál. Dermatosis por IgA lineal vinculada a fármacos. Dermatol Argent 2017;23:42-45.

3. Visentainer L, Massuda JY, Cintra ML, Magalhães RF. Vancomycin-induced linear IgA bullous dermatosis (LABD)-an atypical presentation. Clin Case Rep 2019;7:1091-1093.

4. García García C, Cepeda-Valdés R, Alarcón G, Gómez-Garza AA, et ál. Dermatosis ampollar por depósitos de lgA lineal: reporte de un caso. Medicina Universitaria 2013;15:135-140.

5. Vargas $T J$, Fialho $M$, Santos $L T$, Rodrigues $P A$, Vargas $A L$, Sousa MA, et ál. Linear IgA dermatosis associated with ulcerative colitis: complete and sustained remission after total colectomy. An Bras Dermatol 2013;88:600-603.

6. Baldari U, Raccagni AA, Celli B, Righini MG. Chronic analizado, es posible que cualquier infección pueda desencadenar esta enfermedad por la estimulación del sistema inmunitario ${ }^{6,7}$.

Las manifestaciones clínicas son heterogéneas. Puede manifestarse con pápulas, vesículas y ampollas tensas sobre una base eritematosa, con contenido claro o hemorrágico y disposición en collar de perlas. También se observan áreas de piel denudada, costras y erosiones. El signo de Nikolski puede ser positivo ${ }^{8}$. En los adultos, suele afectar las superficies extensoras de los miembros, el tronco, los glúteos y la cara. En la variedad infantil, es posible encontrar compromiso de los sitios de flexión, los genitales y la zona perioral. Paradójicamente, el paciente analizado padecía esta última variedad, además de la clásica distribución de las lesiones en collar de perlas o rosetas ${ }^{1}$.

En un $50-70 \%$ de los casos, se comprometen las mucosas bucal, ocular, anal, faríngea, laríngea o esofágica. Sin embargo, en el caso presentado, las mucosas se encontraban indemnes?.

En la anatomía patológica, se evidencia una ampolla subepidérmica con contenido de neutrófilos y algunos eosinófilos y, en la dermis, microabscesos de neutrófilos en la punta de las papilas dérmicas. ${ }^{3} \mathrm{La}$ IFD muestra un depósito lineal de IgA en la unión dermoepidérmica, pero también pueden encontrarse C3, IgG e IgM ${ }^{9}$. La técnica de salt-split dependerá del tipo de antígeno implicado, que puede ubicarse del lado epidérmico (BPAg2 clásico) o del lado dérmico (colágeno VII $)^{4}$.

El tratamiento de elección es la dapsona, en dosis de 25 a $300 \mathrm{mg} /$ día, con la que se obtiene una rápida y buena respuesta, además de evitar los desencadenantes. En los casos resistentes, pueden utilizarse corticosteroides en dosis de $1 \mathrm{mg} / \mathrm{kg} /$ día e inmunosupresores como micofenolato en dosis de 1 a $3 \mathrm{~g} / \mathrm{kg} / \mathrm{dí}^{1,10}$.

bullous disease of childhood following Epstein-Barr virus seroconversion: a case report. Clin Exp Dermatol 1996;21:123-126.

7. Alajlan A, Al-Khawajah M, Al-Sheikh $\mathrm{O}$, Al-Saif $\mathrm{F}$, et ál. Treatment of linear IgA bullous dermatosis of childhood with flucloxacillin. J Am Acad Dermatol 2006;54:652-656.

8. Aldama Caballero A, Aquino N, Martínez L, Rivelli V, et ál. Dermatosis IgA lineal. Dos casos con diferentes formas de presentación. Dermatología CMQ 2016;14:204-208.

9. Genovese $G$, Venegoni L, Fanoni $D$, Muratori $S$, et ál. Linear IgA bullous dermatosis in adults and children: a clinical and immunopathological study of 38 patients. Orphanet J Rare Dis 2019;14:1-7.

10. Machado TYS, Enokihara MMSES, lida TM, Porro AM, et ál. Adult linear IgA bullous dermatosis: report of three cases. An Bras Dermatol 2018;93:435-437. 